\title{
Is English an Asian Language?
}

\section{Introduction}

A few years ago, I was standing on a landing of the fire escape stairs of the hotel I was staying at in Bern. It was the evening of Swiss National Day, August 1, and I was standing on the fire-escape as this provided an excellent vantage point for viewing the National Day fireworks. I was not alone, as many of the hotel guests were taking advantage of the view that the fire escape stairs offered. Next to me, two women in their early twenties were chatting to each other. Judging by their conversation, they had only recently met as they were asking each other which country they came from, how long they had been in Switzerland and what their immediate plans were. I gathered from overhearing their conversation that one came from Tokyo and the other from Shanghai. What was remarkable about their conversation was not so much what they were talking about but that they were conducting the conversation in English. They were using English as a lingua franca, as this was the language common to both of them and the one in which they therefore chose to communicate.

A couple of years before that, I was looking around a Thai temple or Wat in Bangkok and stopped to listen to a group of monks chanting their prayers. Just as I was about to move on, the monks finished their prayers, stood up and strolled out of the hall in which they had been praying and were chatting to each other. Despite each of the monks being Asian, they were chatting to each other, not in Thai, as I had assumed they would be, but in English. They were also using English as a lingua franca, the language that these monks shared in common, suggesting that at least some of these monks came from outside Thailand and were not speakers of Thai.

These two vignettes of the use of English as a lingua franca between Asians exemplify how the use and roles of English across Asia has been growing. In this book, I want to briefly trace the history of how English has developed in Asia and then to discuss and illustrate how English is being shaped and reformed to suit the cultures and needs of these Asian users of English. I will therefore consider how new Asian varieties of English such as Indian, Filipino and Singaporean have developed and give examples of the distinctive linguistic and cultural features of these new Englishes. I shall also discuss how the use of English as a lingua franca has grown across Asia and indicate how the use of English as a lingua franca differs from the use of a particular variety of Asian English. Typically, the use of a specific variety of Asian English is more about the speaker's wish to present their identity among people who share the same linguistic and cultural backgrounds, while the use of English as a lingua franca is more about communication between people who come from different linguistic and cultural backgrounds. I will also consider how the perceived need for English throughout Asia has influenced the curriculum of schools and universities throughout the region and ask whether this increase in the teaching and learning of English is not endangering a number of local languages. I hope that by the end of the book the reader will have an answer for the question posed in the title of the book.

Before proceeding, let me explain how I came to be interested in Asia and in how English has developed there. I had, I believe, an idyllic childhood. I arrived in Kuala Lumpur, Malaysiai, when I was 18 months old, in the company of my mother. We had travelled from England to be reunited with my father, who had taken a job as a mining engineer with a company called Harper Gilfillan. We lived in a bungalow at 208 Ampang Road, then set in spacious grounds 
shared by the 'big' house at the far end of the driveway. This is unrecognisable now as 208 Jalan Ampang is now heavily built up and is just up the road from the twin structures of the Petronas Towers, Kuala Lumpur's main landmark, visible from miles away. I spent the next few years playing unhindered and unshod in the wonderful gardens with the children of the compound. These comprised the two expatriate children of the big house, Richard, a year older than me, and Sarah of about my age, and the children of the servants. It was a carefree existence as we explored the gardens - which seemed like jungle to us - and which contained more than 50 coconut palms - and we communicated in an odd mix of Malay, Hokkien - the dialect of Chinese spoken on the compound - and English. This idyllic life continued until I was seven when I was sent home to boarding school in England, where life was somewhat different. I remember hating wearing the school uniform - which required, not surprisingly, socks and shoes, items of clothing I was not used to, having spent most of my childhood to that date running around in bare feet or flip-flops. The food served up at the school was, to me, mainly inedible. I was given special dispensation against porridge after I threw up after the first two times I was required to eat what to me was a foul congealed lumpy mess of goo. The 'knowledge' expected of a boy (it was an all-boys preparatory school) was not knowledge I had acquired. For example, on being asked in class who the Prime Minister was, I replied 'Tunku Abdul Rahman'. This answer was treated with disbelief. 'No, I was told. It's Harold Macmillan'. At that age I did not possess the wit to say that he was not the Prime Minister merely the Prime Minister of Great Britain.'. My man was the PM of newly independent Malaysia.

I then spent the eight weeks of each summer holidays in Malaysia and then Singapore, which is where my father had later been posted, until his untimely death in 1964, whereupon my mother decided to return to live in England. While only lasting for 8 weeks a year, my annual trip back out to the Far East kept me familiar with the languages and the ways they were used, often mixed together, as is the natural way with multilinguals. Thus when it came to wanting to choose what to study at university, I first wanted to opt for Thai and Malay, but there were no undergraduate courses of that type in the UK in 1968, so I ended up studying Chinese at Leeds University. I then, as a postgraduate student, went on to study Chinese literature at Fudan University in Shanghai and did my doctorate in Chinese Rhetoric at the Australian National University. In addition to working at Australian universities, I have worked in tertiary institutions in Myanmar, Singapore, China and Hong Kong.

So, my interest in languages in Asia and how English is being reshaped by its Asian speakers is almost certainly a product of my upbringing. I have been studying Asian varieties of English and the use of English as a lingua franca in Asia for many years, and this book is an attempt to pass on, in an accessible style, what I have learned in the hope that it will be of interest and use to the reader.

As a way of introducing the idea of English as an Asian language I shall start by reviewing an article written by the person whom most see as the founder of the discipline of World Englishes, Braj Kachru. In his article 'English as an Asian Language' (1998) he starts by pointing out that English is usually discussed as being a language that is in Asia but not of Asia. He uses the metaphor 'hydra-headed' to describe English and notes that it is not uncommon to be asked 'Whose language is English anyway?' (1998:91). He goes on to say that 'initiatives in planning, administration and funding for the acquisition and spread of English are primarily in the hands of those Asians who use English as an additional language' 
(1998: 95). In taking this position he opposes the proponents of the theory of Linguistic Imperialism' (e.g. Phillipson 1992) who argue that the increasing spread of English is as the direct consequence of a plot hatched by the governments of English speaking countries and their allies, such as the British Council and Voice of America.. in spreading the gospel, as it were, It is Kachru's belief, however, that world Englishes have a 'plurality of centres' (1998:97) which provide the grammatical norms and models for their acquisition. In the context of Australasia, Kachru argues that first language varieties of English (Australian and New Zealand English, for example) and second language varieties of English (Singaporean and Filipino, for example) provide the norms and models for their speakers. These speakers use an institutionalised variety of English as a result of their colonial histories of having been ruled and / or settled by English speaking countries. In contrast, speakers of English in countries which were not ruled by English-speaking colonial masters use a performance variety of English and they take their norms and models from institutionalised varieties of English. They are, in Kachru's terms, 'norm-dependent' users of English. I shall later argue that the extraordinary increase in the use of English in countries such as China means that they may become norm providers of their own variety of English rather than being normdependent upon an external variety such as British English.

Kachru then asks if there is an Asian canon of English. He believes that there is and he lists five uses of English in Asia (1998:102-3). They are:

(i) as a vehicle of linguistic communication across distinct linguistic and cultural groups;

(ii) as a nativised medium for articulating local identities within and across Asia;

(iii) as one of the Pan-Asian languages of creativity;

(iv) as a language that has developed its own subvarieties indicating penetration at various levels;

(v) as a language that continues to elicit a unique love-hate relationship that, nevertheless, has not seriously impeded its spread, function and prestige.

Kachru further argues that once a language has established its autonomy, it is actually liberated and its 'liberated' uses and functions have to be separated from its non-liberated uses (1998:103). We must shift the focus of enquiry, he proposes, from a monolingual paradigm to 'paradigms relevant and appropriate to multilingual and multicultural societies' (1998: 104). And citing the example of African and Asian writers of literature in English such as Soyinka, Rao and Thumboo, he concludes that one major strategy is to 'acculturate the language in our contexts of use on our terms, on Asian terms' (1998:105).

In this book I shall investigate the development of English(es) across Asia, consider their roles and illustrate ways in which they have 'acculturated' English. I hope to show that the Englishes of Asia have indeed fulfilled each of the five uses identified by Kachru above. Chapter 1 will provide an introduction to how English was introduced and then developed in various settings across Asia and how distinct Asian varieties of English were formed. Chapter 1 will also provide an account of how English came to be ratified in the 2009 Charter of the Association of Southeast Asian Nations (ASEAN) as the sole working language of the group.

Chapter 2 will introduce the Asian Corpus of English (ACE)( http://corpus.ied.edu.hk/ace/) a corpus of naturally occurring English as spoken as a lingua franca by Asian multilinguals. A 
wide range of speech events have been included in ACE: interviews; press conferences; service encounters; seminar discussions; working group discussions; workshop discussions; meetings; panels; question-and-answer sessions; and conversations. The transcribed speech events are categorized under five major settings: education (25\%), leisure (10\%), professional business (20\%), professional organisation (35\%), and professional research/science (10\%). The ACE corpus was collected to act as a complementary corpus to the Vienna Oxford International Corpus of English (VOICE) (https://www.univie.ac.at/voice/), collected by Barbara Seidlhofer and her team at the University of Vienna. VOICE is a corpus of naturally occurring English being used as a lingua franca in primarily European settings. The ACE corpus data have been tagged following the transcription conventions originally developed by the VOICE project team. These tags enable us to obtain a clear picture of the transcribed data (e.g., pauses, overlaps, pronunciation variations \& coinages), and make ACE and VOICE comparable. Users can browse the corpus data according to the five types of setting (as listed above) or according to the various data collection sites (Hong Kong, Malaysia, Philippines, Vietnam, Singapore, Brunei, Japan, Mainland China, and Taiwan). A Web concordancer has been developed which allows users to search any word/phrase in ACE, and collocation information of the search word/phrase will be illustrated. Other than searching the corpus, users can also listen to the sound recording of certain ACE files, and the transcripts are shown line by line on screen synchronously with the sound played. These functions have made it possible for researchers and teachers/learners to explore the ACE data for various research and pedagogical purposes.

Chapter 3 discusses and contrasts Asian varieties of English with the use of English as a lingua franca in Asia. Examples from selected varieties of Asian Englishes are presented. These examples will show how Asian varieties of English are typically code-mixed varieties as speakers use their shared linguistic resources as markers of identity. It must be underlined that the great majority of users of Asian varieties of English have learned English as an additional language and are speakers of other languages. Their variety of English will include linguistic features and items from their speakers' other languages. For example, the colloquial variety of Singaporean English typically consists of English mixed with linguistic items and features from local languages such as Malay and varieties of Chinese. An Asian variety of English is used by people who share the same cultural and linguistic repertoires. These Asian varieties of English are then compared and contrasted with the use of English as a lingua franca in Asia, illustrating, for example, how code-mixing from other language is reduced as the primary function of the use of a lingua franca is communication across cultural and linguistic boundaries.

Chapter 4 provides empirical evidence for the claim that English is an Asian and Asia-centric language. Using data from ACE, topics that Asian multilinguals typically talk about when using English as a lingua franca are described and illustrated. A preliminary study into this, using a small subset of the ACE corpus, found that common topics were, perhaps not surprisingly, Asia-centric. The topics discussed ranged from the relatively light hearted such as comparing in a jokey fashion the various qualities of different brands of Thai and Malaysian rice and the importance of coffee to the Vietnamese - to more serious topics such as the treatment of Burmese refugees, ways of raising Islamic finance and the prejudice shown towards ethnic minorities in Hong Kong (Kirkpatrick, Patkin and Wu 2013). This chapter will also introduce the fundamental concepts of register and levels of formality by 
illustrating how different topics call for different speech styles and types of interaction. The chapter will include a critical discussion on the implications of the topics commonly discussed by Asian multilinguals for English language teaching, in particular their implications for relevant materials and curricula. It will be argued, for example, that topics found to be commonly discussed by Asian multilinguals could provide excellent materials for Asian multilinguals who are learning English to use with their fellow Asians.

Chapter 5 will provide further evidence that English is an Asia-centric / Asian language. Again using empirical data from ACE and from a selection of Asian varieties of English, how local and regional cultural and pragmatic norms are realised in the English being used by Asian multilinguals will be illustrated. Questions to be considered include 'Do Asian multilinguals use their own cultural and pragmatic norms when using English? For example, I will show how discourse markers can be transferred from the speakers' first languages to mark levels of formality and informality while using English. I also investigate whether there is empirical evidence for the idea that there is an 'Asian' way of communication which is marked or characterised by dialogue and consensus (the English translations of two key words in Malay, namely musyawarah and muafakat [Curley and Thomas 2007:9]). It so happens that ACE has recordings of consular officials discussing this very issue and this will be analysed and discussed. The presence or otherwise of local or regional cultural conceptualisations (Sharifian 2010) in the English as a lingua franca of these interactants will also be considered. For example, Kirkpatrick and Xu (2012) have shown that Chinese speakers typically prefer to preface requests with reasons or justifications for such requests. This contrasts with native speakers of American English who typically prefer to make the request early in the interaction (usually softened with some form of moderation) and then provide reasons if required. So, a question to be examined is whether request patterns in ACE tend to follow a 'reasons for request $\rightarrow$ request' pattern or a 'request $\rightarrow$ reasons for request' pattern. This chapter also provides a description and discussion of the communicative strategies of Asian multilinguals. Questions to be addressed include whether there is evidence to support the claim that users of English as a lingua franca seek cooperation and strive to ensure communicative success. Is there evidence to support the existence of an Asian/ASEAN way based on dialogue and consensus? Is there evidence to support the existence of face-threatening and face-challenging behaviour in certain contexts? In an earlier study which used a subset of the ACE corpus, Kirkpatrick (2010b) identified 15 speaker and listener strategies adopted by Asian multilinguals while using English as a lingua franca. Speaker strategies included spelling out the word, repeating the phrase, being explicit, using paraphrase and the avoidance of idiomatic references. These findings supported other findings using more European-based data, illustrating that English as a lingua franca is characterised by ELF speakers' adoption of specific communicative strategies to ensure successful communication and the preservation of their fellow interlocutors' face. The editors of a review of trends in ELF research conclude that these trends 'evidence the supportive and cooperative nature of interactions in ELF where meaning negotiation takes place at different levels' (Archibald, Cogo \& Jenkins, 2011, p. 3). House has spoken of the 'solidarity of nonnative ELF speakers' (2003, p. 569). Findings pointing to the cooperative nature of ELF interactions have also been reported by Firth (1996) and Meierkord (2012). Firth identified strategies such as the 'let it pass' principle, whereby speakers, instead of seeking immediate clarification when they did not understand what a speaker was saying, would let it pass, hoping, often correctly, that the meaning would become clear later. Meierkord's findings 
indicate that 'the conversations are characterised by their participants' desire to render the interactions normal and to achieve communicative success' (2012, p. 15). Once again, it will be argued that context is the crucial variable, as, in a more recent study, Kirkpatrick, Subhan and Walkinshaw (2014), it was found that there were occasions when speakers, far from seeking to preserve the face of their fellow interlocutors, were happy to threaten their interlocutors' face. For example, in the courtroom exchanges in the ACE data, perhaps not surprisingly, direct, confrontational questioning and bald-on-record disagreement are common currency, where winning the argument supersedes the desire for interactional comity.

Chapter 6, using data primarily from Asian varieties of English, will describe, illustrate and analyse the use of words and idioms from the speakers' first languages when they use English. It thus considers further evidence for English used in these contexts being an Asiacentric or Asian language. Questions to be considered when dealing with distinctive lexical features include the role of words/idioms from the speakers' first language and / or code mixing and a comparison of their use when speakers are using their Asian variety of English and when English is being used as a lingua franca. If code-mixing is used, what might the reasons for this use be? If code mixing is not used, what might the reasons for the lack of use be? It is generally expected that, as with varieties of English everywhere, speakers will use words from local languages which reflect local phenomena of one sort or another.

Developing the arguments presented in Chapter 3, I shall consider the hypothesis that, when English is used as a specific Asian variety among people who belong to the same or similar speech communities, it will be natural for them to code-mix and use many words from their respective languages as these languages are shared and interactants can be expected to understand them. This use of language is also a key marker of identity. On the other hand, when English is used as a lingua franca, it might be expected that speakers would use fewer words and expressions from their first languages because these might not be known by their fellow interactants. A preliminary study using ACE data (Kirkpatrick and McLellan 2012) supported this hypothesis, but work on the VOICE corpus showed a frequent use of the speakers' first languages (e.g., Pitzl 2012). In this chapter, this will be investigated further the possibility examined that, when the speakers' languages are cognate and belong to the same language families - as is the case with many European languages - there may be more of a tendency to use words from a variety of first languages. But where the languages are not cognate and belong to different language families - as is the case with many Asian languages - this tendency may not be so prevalent. Chapter 6 will also provide examples from Asian literatures written in English to show how Asian writers have 'stretched' and 'adapted' English to reflect their cultural values and lived experiences.

Chapter 7 will investigate the use, environment and frequency of non-standard morphosyntactic forms in English when used (i) as a specific variety of Asian English and (ii) when used as a lingua franca by Asian multilinguals. Major questions to be considered when dealing with distinctive morpho-syntactic features include an investigation into the role of the speakers' first languages in the creation of distinctive/non-standard forms or whether there is evidence for the existence of vernacular universals. In a preliminary study based on a subset of the ACE corpus, Kirkpatrick and Subhan (2014) considered the hypothesis that the speakers' first language or substrate would be significant in their use of non-standard forms. The specific question addressed was whether those speakers whose first language was Malay, a language 
which does not mark for tense, would therefore tend not to mark for tense when using English. A study of a group of speakers of varieties of Malay did not support the hypothesis. On the contrary, it was found that, in formal occasions, first language speakers of Malay very seldom failed to mark for tense; and even in more informal situations, they marked for tense more often than not in a ratio of 3:2. This illustrates the importance of corpora for investigating the comparative frequency of distinctive morpho-syntactic features and the crucial significance of context and levels of formality. The results here supported recent findings of scholars such as Sharma who has argued convincingly that "the degree and distribution of a given feature must be understood in relation to the substrate before any universal claims can be made" (2009: 191). The findings also supported those of Hall et al. (2013:15) who, in their study of the occurrence of countable mass nouns, concluded that first the language substrate influence was not high and that the countable use of mass nouns, while being widespread and attestable across speakers of different languages, was also infrequent, with a maximum occurrence rate of only $3.5 \%$.

Chapter 8 considers a selection of functions that English is playing in Asian countries. I first consider the role that English is playing in the legal systems of many post-colonial countries, even though these countries have been independent for several decades. The recent widespread protests in Hong Kong against a proposed law that would allow the extradition of people from Hong Kong to face the court system of Mainland China is a prime example of how people may still regard the colonial legacy of English law to be more transparent and just than local systems of law. This chapter also looks at how English has been adopted for use in religion. For example, I report on how certain schools attached to mosques in Indonesia now teach courses in 'English for Islamic Values', providing further evidence of how its new users are adopting English for their own cultural practices and purposes. Chapter 8 concludes with examples of how English is being used in popular culture across Asia.

Chapter 9 will consider the role of English as a language of education across the region, including brief reviews of its role in primary, secondary and higher education in selected settings. It will review and critically consider language education policies that have been adopted in selected countries. The second half of the chapter will turn to a review and critical discussion of the increasing use of English as the medium of instruction in higher education across universities in the region. The chapter will conclude by arguing that language education policies need to be considered holistically and be coherent from primary to tertiary education. Otherwise there is a danger of English replacing local languages as languages of education and scholarship.

Chapter 10 will present a proposal based on the findings and data discussed earlier for a lingua franca approach to English language teaching for the region. This will extend the proposal made by Kirkpatrick $(2014,2018)$ in which principles of the lingua franca approach to English language are presented and discussed. The lingua franca approach is proposed as a way of both ensuring that English is successfully learned by Asian multilinguals while, at the same time, ensuring the preservation of local languages as languages of education.

The concluding chapter will first draw together the empirical findings and return to the five uses of English in Asia identified by Kachru and which were discussed above. I will argue that English is developing new domains of use and that an increasing number of Asians are becoming highly proficient speakers of English and who are shaping English to their own 
uses and cultures, allowing them to develop a sense of ownership of the language. English is now an Asian language, both in and of Asia. This conclusion comes with no sense of triumphalism. On the contrary, the chapter will conclude with the prediction that, unless regional governments develop holistic and coherent language education polices, it is likely that English will continue to increase its range at the expense of local and regional languages. The region needs to find a way in which English can co-exist with regional languages. As argued in Chapters 9 and 10, delaying the introduction of English while students develop literacy and fluency in their respective national language and, where practical, their home language, is a possible solution. It may seem counter-intuitive, but delaying the introduction of English will result in a win-win solution through which students can graduate from secondary school, proficient in English and fluent and literate in their respective national language and their home language.

Before moving to Chapter 1, I need to first to add a caveat and then indicate just how many users of English there are in Asia today. First, the caveat: Asia is a vast area and I cannot cover all of it. I shall focus on selected countries of South Asia, East Asia, and on Southeast Asia, in particular the ten countries which comprise the Association of Southeast Asian Nations (ASEAN). Second, just how many users of English are there in Asia today? Estimating numbers of speakers of English in Asia is an inexact science, but the most accurate figures are provided by Bolton and Bacon-Shone (2020). Using census and language survey data they compiled figures for speakers of English in specific countries of Asia. Tables 1 and 2 below are adapted from Bolton and Bacon-Shone (2020). Outer Circle countries are those which were previously colonies of English speaking nations and where English retains some institutional role. Expanding circle countries are those countries where English has traditionally been learned in school as a foreign language. The third circle, the Inner Circle countries, are those where English is the main language and where it is spoken as a first language, as in the United States or the United Kingdom. This 'circles classification' was made by Kachru (1992) and we shall be referring to it throughout the volume.

Table 1. Knowledge of English in Outer Circle Asian societies

\begin{tabular}{lcc}
\hline Society & Current estimates & $\begin{array}{c}\text { Approx. total of } \\
\text { English speakers }\end{array}$ \\
\hline Singapore $\dagger$ & $80 \%$ & 3.1 million \\
Philippines $\dagger$ & $65 \%$ & 66.7 million \\
Brunei $\dagger$ & $60 \%$ & 0.2 million \\
Hong Kong $\dagger$ & $53 \%$ & 3.9 million \\
Malaysia & $50 \%$ & 15.5 million \\
Pakistan & $25 \%$ & 50.9 million \\
Sri Lanka $\dagger$ & $25 \%$ & 5.3 million \\
Bangladesh & $20 \%$ & 32.6 million \\
India & $20 \%$ & 260.0 million \\
\hline Total & & $\mathbf{4 3 8 . 2}$ million \\
\hline
\end{tabular}

Table 2. Knowledge of English in Expanding Circle Asian societies

\begin{tabular}{lcc}
\hline Society & Current estimates & $\begin{array}{c}\text { Approx. total of } \\
\text { English speakers }\end{array}$ \\
\hline Nepal & $30 \%$ & 8.5 million \\
Macau $\dagger$ & $28 \%$ & 0.2 million
\end{tabular}




\begin{tabular}{lcc} 
China & $20 \%$ & 276.0 million \\
Myanmar (Burma) & $10 \%$ & 5.2 million \\
Japan & $10 \%$ & 12.5 million \\
South Korea & $10 \%$ & 5.1 million \\
Taiwan & $10 \%$ & 2.4 million \\
Thailand & $10 \%$ & 6.5 million \\
Vietnam & $10 \%$ & 4.6 million \\
Cambodia $\dagger$ & $5 \%$ & 0.8 million \\
Indonesia & $5 \%$ & 13.0 million \\
Laos & $5 \%$ & 0.3 million \\
\hline Total & & $\mathbf{3 3 5 . 1}$ million \\
\hline
\end{tabular}

Adding the number of people who know English from both tables, we get a total of 773.3 million. This figure vastly exceeds the number of first language users of English in the United Kingdom and the United States, with populations of 66 million and 324 million respectively. And it needs to be remembered that many British and Americans do not speak English as a first language. So, while stressing that it is difficult to obtain accurate figures of the number of Asians who use English, we can safely conclude that there are more Asian users of English than there are native speakers of it. I now turn to consider the development of English in Asia.

\footnotetext{
' It was still Malaya then as I arrived in 1951 and Malaya received independence to become Malaysia in 1957.
} 